\title{
Panels made from recycled tire-application of linear model to test the tensile force
}

\author{
Andjelko Crnoja \\ Odessa State Academy of Civil Engineering and Architecture
}

\begin{abstract}
Background: Number of used tires is increasing every day and the accumulation of such waste is a serious problem in terms of environmental protection and in terms of delay and deposition (End-of-LifeTires, 2019). Over the last twenty years the study of new ways to use products from recycled tires has been intensified. When developing new products, it is important to investigate how certain properties of the materials used change. According to the available literature, different variants of material composition and processing approaches have been investigated (Kowalska, Chmielewski, Guleira \& Dutta, 2017; Zaoiai, Makani, Tafraoui \& Benmerioul, 2015). Objectives: The aim of this work, based on the evaluation of an experiment using a mathematical model, is to determine the required structure of the material. The possibility and correctness of using the linear model was determined. Methods/Approach: The experiment was conducted to check the magnitude of the deformation depending on the stress. Results: Based on the obtained results, the accuracy of the applied linear model and the influence of individual factors on the results of the experiment were evaluated. Conclusions: Mathematical linear model estimation refers to the determination of quantitative parameters in the structure of a material. If the required deformation is defined or acceptable, other material parameters can be determined with some accuracy.
\end{abstract}

Keywords: mechanical properties, linear model, rubber crumb, tensile, deformation

Paper type: Research article,

Received: 29. 4. 2020.

Accepted: 23. 6. 2020.

DOI: $10.2478 /$ crdj-2021-0001

\section{Introduction}

Technological development, increased production and economic growth increase the demand for the production of building materials. On the other hand, increasing the amount of waste is a big problem in all countries of the world. The authors (Farrag, Ibrahim \& Elalfy, 2017) cited Egypt as an example and explain how large financial resources are spent on the reconstruction of landfills in that country. They also indicate the reasons why used car tires can become a serious environmental problem and adversely affect human health. 
Tire volumes in developed countries are decreasing, while in less developed countries, this waste is accumulating. An example is South Africa, with an estimated 800 million consumed tires and 1-2 billion in Mexico (End-of-LifeTires, 2008). Some studies show a direct relationship between the worn tire and the occurrence of certain serious human diseases (Marsili, Coppola, Bianchi \& Fossi, 2014; Beausoleil, Price \& Muller, 2009; Swedish Chemicals Inspecorate, 2006; Cardno Chem Risk, 2013, Boccaa, Forte, Petrucci, Costantini \& Izzo, 2009; IARC, 1983). Long studies and tests show how these particles separate from the wheels when using and driving on roads and penetrate the human body (Panko, Kreider, McAtee \& Marwood, 2010; McAtee, Kreider, Panko \& Finley, 2012).

In 2007, the European Commission issued a Directive (European Commission, 2007) aimed at making the dismantling and decommissioning of used tiers and their components environmentally friendly. Currently, the author, available literature (Guleira \& Dutta, 2012; Kowalska, Chmielewski, Guleira \& Dutta, 2017; Zaoiai, Makani, Tafraoui \& Benmerioul, 2015) discusses using of recycled rubber as admixtures of mixtures of concrete, gypsum, asphalt, geotechnical applications, etc. All of these studies suggest an additive, not a finished and applicable product.

The author wants to show that recycled rubber can be used and applied to industrial and residential buildings in such a way that it actively participates in the protection of the structure and interior or exterior in different types of insulation, primarily in the protection against noise. Using samples from the recycled tires as independent material is intended to show that such type of material is applicable. It is known that the material needs to be treated with certain liquids that will neutralize odours, prevent erosion in terms of the formation of micro and nano particles that can enter the body, all in order to obtain a specific product.

Recently, a lot of time and resources have been spent on solving these problems. In addition to environmental protection, the disposal of such waste is a significant result of the production of new products as a result of recycling in various fields.

The world's major economies have shown that it is profitable to recycle rubber and with a well-thought-out strategy, new jobs can be created. The situation in Croatia and neighboring countries is such that there are few car tire processors.

The leading company is "Gumiimpex", which in several of its plants recycles and manufactures certain products. However, this production is minimal and insufficient to take over rubber-based waste in Croatia and its surroundings. A large part is exported as rubber granules (semi-finished product, raw material) for large processors.

Certain studies have shown that products can be put into mass consumption in construction, and the design of such products can stimulate production, regional development and provide multiple positive effects on environmental protection. Tests show that the market has the potential to be used to open new plants to produce new products.

This study aims to evaluate the mechanical properties of recycled rubber using a statistical linear model. The properties were evaluated based on an experiment conducted on an axial tensile tester.

\section{Methodology}

The experiment was performed on calibrated devices. The reason for this is the control and the accuracy of measurements. The devices were properly selected and used. Certain deviations or measurement errors are taken into account and accounted for in the 
final result. The testing equipment was easy to use. The recycled rubber samples were made in accordance with HRN EN ISO 527-4: 2008 "Determination of the tensile properties of plastic materials" and were tested on AXIS FB $20 \mathrm{~K}$ axial equipment as shown in Figure 1.
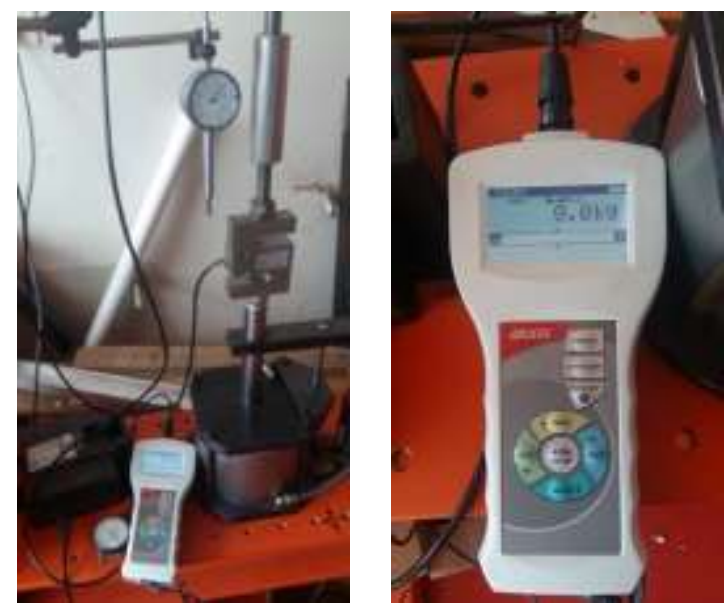

Figure 1

Equipment for conducting the experiment

Source: Author's illustration

When using this device, it is possible to apply force to the sample manually and hydraulically. When high forces are applied, the load is exerted by the hydraulic pump and smaller loads are produced manually. In the case of the experiment the force was applied manually at regular intervals corresponding to the amount of strain. For easier monitoring, it is recommended that the value of the applied force acting on the sample be an integer. Water-based pressure cutting technology was used in the preparation and production of the samples. Depending on the size of the sample, the operation can be performed by cutting with a jet or with finished tools for this purpose. The water jet cutting device can be seen in Figure 2.
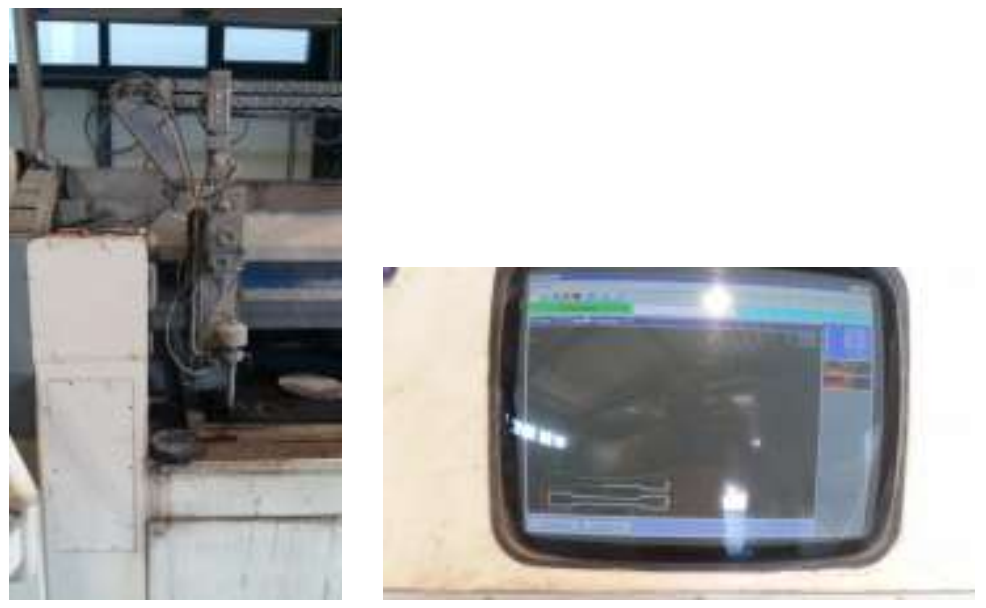

Figure 2

Water jet sampling equipment 
Source: Author's illustration

The sketch and sample dimensions are visible in Figure 3. The sketch has been prepared in accordance with the applicable standard while the cutting is performed on a device operated by a computer. The contours of the cuts visible on the monitor. Two identical samples were prepared, which were cut at the base at the same time. The cut should be nice and without any damage to the sample, which can weaken the sample on the test area. Such sample would be destroyed and the measurement would be defective. A sample sketch can be seen in Figure 2 .

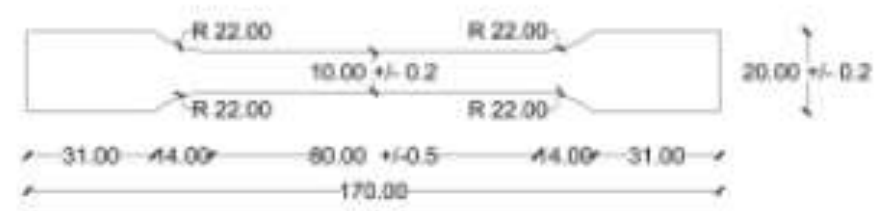

Figure 3

Sample scheme according to standard

Source: Author's illustration

In the experiment we used samples of different thickness, the specific gravity of the binder content. The thickness of the samples varied and ranged from 10 to $20 \mathrm{~mm}$. Specific mass of the samples ranged from 585 to $916 \mathrm{~kg} / \mathrm{m} 3$. The specification of the samples is shown in Table 1. The samples also show a thickness of $10 \mathrm{~mm}$, with a specific mass of $585-600 \mathrm{~kg} / \mathrm{m} 3$ not even made.

\section{Table 1}

Technical characteristics of test samples

\begin{tabular}{|c|c|c|c|c|}
\hline \multirow{5}{*}{$\begin{array}{c}\text { Granulometric } \\
\text { compositio } \\
\mathbf{n}\end{array}$} & $\begin{array}{l}\text { № } \\
\text { sample }\end{array}$ & $\begin{array}{c}\text { № } \\
\text { sample }\end{array}$ & $\begin{array}{c}\text { № } \\
\text { sample }\end{array}$ & \multirow{2}{*}{$\begin{array}{c}\text { Thickness of } \\
\text { the } \\
\text { sample, } \\
\text { mm }\end{array}$} \\
\hline & $\begin{array}{r}700-750 \\
\mathrm{~kg} / \mathrm{m} 3\end{array}$ & $\begin{array}{r}900-916 \\
\mathrm{~kg} / \mathrm{m} 3\end{array}$ & $\begin{array}{r}585-600 \\
\mathrm{~kg} / \mathrm{m} 3\end{array}$ & \\
\hline & 1 & 4 & * & 10 \\
\hline & 13 & 16 & 10 & 15 \\
\hline & 22 & 25 & 19 & 20 \\
\hline
\end{tabular}

Note: * - no sample was created in this category (valid for the indicated specific mass)

Source: Author

The samples were made with the same particle size distribution of $0.5-2.0 \mathrm{~mm}$ (Gumiimpex, 2020) with different specific gravities from $585 \mathrm{~kg} / \mathrm{m} 3$ to $916 \mathrm{~kg} / \mathrm{m} 3$ (Table 1), different thicknesses of 10,15 to $20 \mathrm{~mm}$ and different weights of polyurethane adhesive binder (Table 2).

\section{Table 2}

Quantity of binder in samples / material 


\begin{tabular}{ccccccccc}
\hline $\begin{array}{c}\text { No } \\
\text { sam } \\
\text { ple }\end{array}$ & 1 & 13 & 22 & 4 & 16 & 25 & 10 & 19 \\
\hline $\begin{array}{c}\text { Glue } \\
\text { g/m2 }\end{array}$ & 296 & 475 & 1100 & 380 & 580 & 1340 & 380 & 858 \\
\hline
\end{tabular}

Note: * - binder quantity refers to the sample surface for the given parameters

Source: Author

Testing the samples for the effect of tensile forces, the following results are shown in Figure 4.

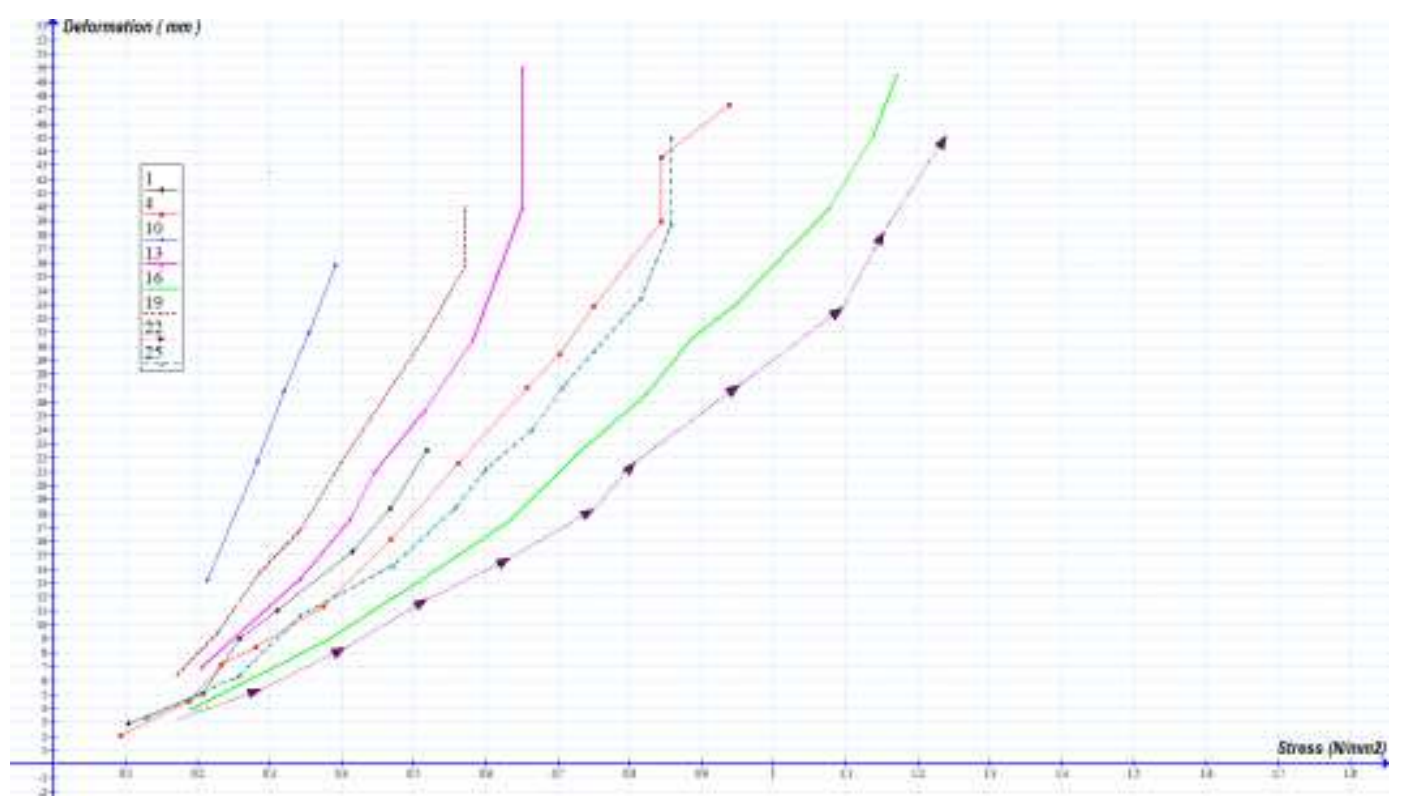

Figure 4

Diagram of the test results of tensile properties

Source: Author's illustration

For the obtained results a linear regression model was constructed and analysis required to understand the behaviour of the material under the conditions of given loads has been done. The SPSS software package was used to process the results.

Model. Accordingly, the normality of the distribution was tested on the prepared model. The Kolmogorov-Smirnov test was used for this purpose and the results are shown in Table 3.

\section{Table 3}

Kolmogorov-Smirnov Test

One-Sample Kolmogorov-Smirnov Tests

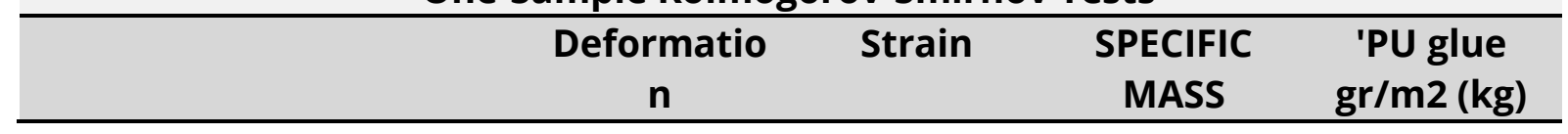




\begin{tabular}{|c|c|c|c|c|c|}
\hline & & & \multicolumn{3}{|c|}{$(\mathrm{t} / \mathrm{m3})$} \\
\hline \multicolumn{2}{|c|}{$\mathbf{N}$} & 87 & 87 & 87 & 87 \\
\hline \multirow{2}{*}{$\begin{array}{c}\text { Normal } \\
\text { Parameter } \\
\text { sa,b }\end{array}$} & Mean & 22,46 & ,55670 & ,822080 & ,689080 \\
\hline & $\begin{array}{c}\text { Std. } \\
\text { Deviation }\end{array}$ & 13,746 & ,294599 & , 1505928 & ,3600627 \\
\hline \multirow{3}{*}{$\begin{array}{c}\text { Most } \\
\text { Extreme } \\
\text { Differences }\end{array}$} & Absolute & ,087 & ,087 & ,215 & ,251 \\
\hline & Positive & ,087 & ,087 & ,167 & ,251 \\
\hline & Negative &,- 068 &,- 058 &,- 215 &,- 137 \\
\hline \multicolumn{2}{|c|}{ Kolmogorov-Smirnov Z } & ,811 & ,812 & 2,004 & 2,343 \\
\hline \multicolumn{2}{|c|}{ Asymp. Sig. (2-tailed) } & ,526 &, 525 & ,001 & $<, 001$ \\
\hline
\end{tabular}

a. Test distribution is Normal.

\section{b. Calculated from data.}

Source: Author

The empirical K-S value was also tested, and the test results are in Table 4.

\section{Table 4}

Model characteristics according to $\mathrm{p} \mathrm{K-S}$

\begin{tabular}{lcccc}
\hline & \multicolumn{5}{c}{ Empirical p K } \\
\hline Empirical p K & $\mathbf{R}$ & R Square & $\begin{array}{c}\text { Adjusted R } \\
\text { Square }\end{array}$ & $\begin{array}{c}\text { Std. Error of } \\
\text { the } \\
\text { Estimate }\end{array}$ \\
\hline Empirical p K &, $882 a$ &, 778 &, 770 & 6,593 \\
\hline
\end{tabular}

Source: Author

The empirical $p$ K-S value of 0.526 indicates that the dependent variable in the selected sample is usually distributed, the strain variable is also usually distributed, while the values of other independent variables are usually not distributed ( $p p$ values less than $5 \%)$.

The value of the determination coefficient of 0.778 suggests that the influence of deformation, material density and thickness on the deformation is interpreted as $77.8 \%$ of the change in the size of the deformation.

Multicollinearity is a potential problem in the model and has been tested.

\section{Table 5}

Determination of multicollinearity 


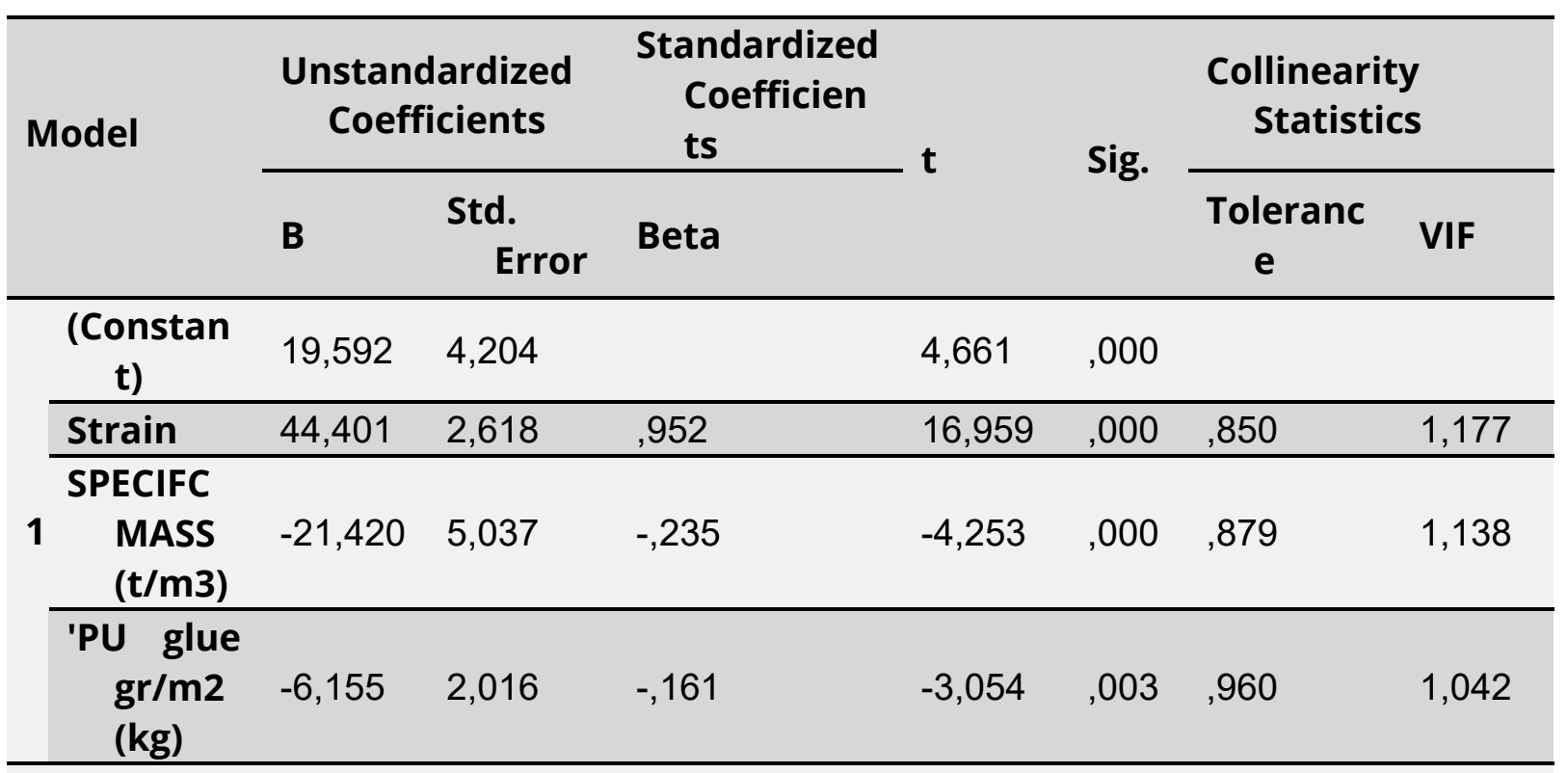

a. Dependent Variable: deformation

Source: Author

VIF values do not exceed limit value 5 , so it has been determined that a potential multicollinear problem has been resolved.

The problem of heteroskedasticity did not exist since there was no correlation between lagged

deviations

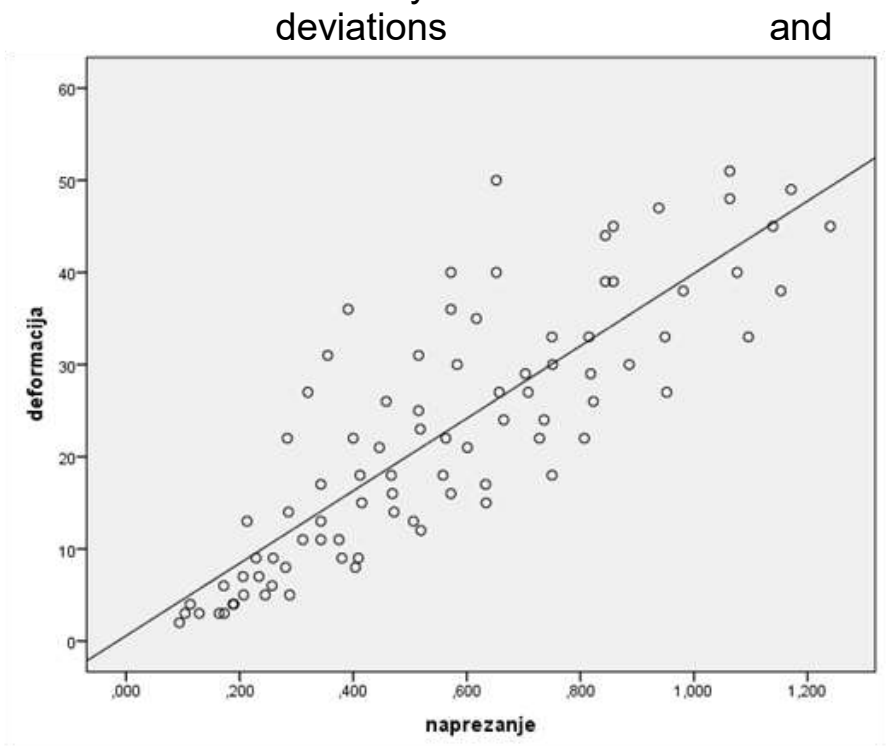

variables.

Figure 5

Deformation-strain relationship in a linear model

Source: Author's illustration

Based on the obtained formed model:

$$
\delta=19,592+44,401 \times n-21,420 \times \rho-6,155 \times P u
$$


where:

$\sigma$ - expected deformation, $\mathrm{mm}$

$\mathrm{n}$ - strain, $\mathrm{N} / \mathrm{mm} 2$

$\rho$ - specific gravity, $\mathrm{kg} / \mathrm{m} 3$

$\mathrm{Pu}$ - amount of polyurethane glue, $\mathrm{kg} / \mathrm{m} 2$

Model management implementation and statistical value of the model. The test was performed with the Spearman correlation, and was conducted because of the possible relationship between the unstandardized residual values and the independent variables

Table 6

Model testing with Spearman correlation

Correlations

\begin{tabular}{llc}
\hline & & Unstandardized Residual \\
\hline \multirow{3}{*}{ Strain } & \multicolumn{1}{l}{ Correlation Coefficient } &, 032 \\
\cline { 2 - 3 } & Sig. (2-tailed) &, 767 \\
\cline { 2 - 3 } $\mathbf{N}$ & Correlation Coefficient & 87 \\
\cline { 2 - 3 } SPECIFIC MASS (t/m3) & Sig. (2-tailed) &, 012 \\
\cline { 2 - 3 } & $\mathbf{N}$ &, 910 \\
\hline \multirow{3}{*}{ SPECIFIC MASS (t/m3) } & Correlation Coefficient &, 07 \\
\cline { 2 - 3 } & Sig. (2-tailed) &, 678 \\
\cline { 2 - 3 } & $\mathbf{N}$ & 87
\end{tabular}

**. Correlation is significant at the $\mathbf{0 . 0 1}$ level (2-tailed).

*. Correlation is significant at the 0.05 level (2-tailed). 


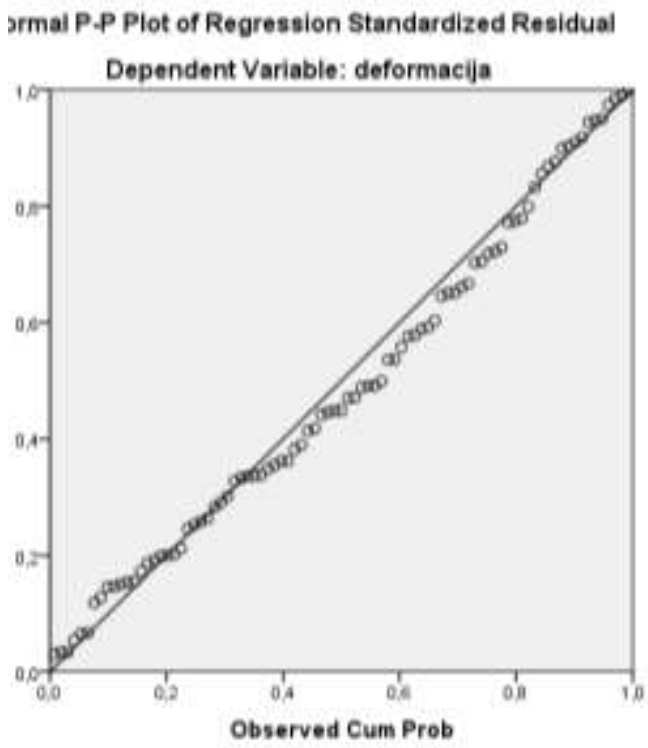

Figure 6

Spearman's connectivity check

Source: Author's illustration

When checking the relationship between non-standard residual values and independent variables, no correlation was found ( $p$ values are greater than 0.05 ), which indicates that there are no inaccuracies in the model. Observing the trend curve, you can see that the results are located in a very close area and that there is not much scattering.

The statistical significance of the model as a whole was verified using an ANOVA test.

Table 7

Testing the model with ANOVA test

\begin{tabular}{|c|c|c|c|c|c|c|}
\hline \multicolumn{7}{|c|}{ ANOVAa } \\
\hline & & $\begin{array}{l}\text { Sum of } \\
\text { Squares }\end{array}$ & df & $\begin{array}{l}\text { Mean } \\
\text { Square }\end{array}$ & $\mathbf{F}$ & Sig. \\
\hline \multirow{3}{*}{1} & $\begin{array}{l}\text { Regressio } \\
\mathrm{n}\end{array}$ & 12641,489 & 3 & 4213,830 & 96,934 & ,000b \\
\hline & Residual & 3608,120 & 83 & 43,471 & & \\
\hline & Total & 16249,609 & 86 & & & \\
\hline \multicolumn{7}{|c|}{ a. Dependent Variable: deformation } \\
\hline \multicolumn{7}{|c|}{ b. Predictors: (Constant), 'PU glue gr/m2 (kg), SPECIFIC MASS (t/m3), STRAIN } \\
\hline
\end{tabular}

\section{Source: Author}

Based on the empirical value $F=96.93$, it is concluded that the estimated model as a whole is statistically significant. The conclusion was drawn at the empirical level of significance $<0.001$. 


\section{Results}

When examining the results, using statistical tools, it was concluded that the set of models is reliable with an accuracy of $78 \%$ in the estimation of deformation depending on their stress, which is visible in Table 4. The model also assumes certain spatial effects between the proposed parameters and is visible in Table no. 8:

\section{Table 8}

Results of the relationship of certain factors material

\section{Descriptive Statistics}

\begin{tabular}{llccl}
\hline \multicolumn{2}{c}{ Mean } & Std. Deviation & $\mathbf{N}$ & \\
\hline Deformation & 22,46 & 13,746 & 87 \\
\hline Strain &, 55670 &, 294599 & 87 \\
\hline $\begin{array}{l}\text { SPECIFIC } \\
\text { (t/m3) }\end{array}$ & MASS &, 822080 &, 1505928 & 87 \\
\hline $\begin{array}{l}\text { 'PU glue } \\
\text { (kg) }\end{array}$ & gr/m2 &, 689080 &, 3600627 & 87 \\
\hline
\end{tabular}

Note: basic model parameters

Source: Author

The table shows the following:

- The average deformation is $22.46 \mathrm{~mm}$ with an arithmetic mean deviation of $13.74 \mathrm{~mm}$.

- Force applied resulted in deformation at which the average stress level was 0.5567 and the average arithmetic deviation was 0.295.

- Average specific gravity was $0,822 \mathrm{t} / \mathrm{m} 3$ with an arithmetic mean deviation of $0,151 \mathrm{t} /$ m3.

- The amount of glue in samples averaged $0.822 \mathrm{~kg} / \mathrm{m} 2$ with an arithmetic deviation of $0.36 \mathrm{~kg} / \mathrm{m} 2$.

Based on the newly formed model, the following were obtained:

- With a one-time increase in stress, the voltage rises on average $44.40 \mathrm{~mm}$.

- As the specific mass per unit increases, the deformation drops on average $21.42 \mathrm{~mm}$.

- By increasing the amount of PU glue by $1 \mathrm{~g} / \mathrm{m} 2$, the deformations are reduced by 6,155 $\mathrm{mm}$.

Figure 4 shows, according to the position of the deformation curves, the relations between the samples and that the elastic properties associated with the deformation are greater for samples with a higher specific mass. It is also seen that a significant increase in the force is required for permanent deformation and breakage, which is directly related to the increase of the binder within the material structure.

Figure 5 shows that the results at lower values of the applied force and the resulting deformation are very close to the tendency curve, while with the increase of the force and the deformation there is a "dissipation" and distance from the tendency curve. This results in a decrease in the percentage of model estimation accuracy. 
The biggest relative influence on the deformation is the stress where any change of stress for one standard deviation can be expected to increase the deformation by an average of 0.952 standard deviations.

\section{Discussion}

The model turned out to be good in terms of approach to solving problems. However, its accuracy is $78 \%$, and $80 \%$ is not required to be considered acceptable. Given a slight lag to the required limit, it was found that the results can be processed statistically, but with a change in the model, until the accuracy is within acceptable limits. Since it was shown that there is increased "scattering" around the trend curve, this is considered the reason why the model did not give satisfactory results.

\section{Conclusion}

When applying statistical models, it is important to emphasize that the accuracy of the estimation refers to deviations from the average value or from the arithmetic mean of the presented results. This study is an indication that on this number of samples with the default parameters are not capable of being applied linear model. The accuracy obtained is $78 \%$ and the required minimum accuracy is $80 \%$. It is necessary to increase the number of samples tested or continue processing with another more complex model.

The results of the study form a model for estimating certain deformations with respect to given parameters. This directly indicates that the recipe of the material may be affected by deformation. If the required recipe is known, there is also an impact on the economic aspect of the material.

In order to continue processing the results by statistical methods, exponential or logarithmic functions will be used in the continuation of the study, which can give better and more accurate processing of the results and thus a more accurate model for estimating the deformation values for given parameters. Ultimately, with this approach, the composition of the material can be modelled and the parameters required for the purposeful use of the finished product can be affected.

\section{References}

End-of-LifeTires, WorldBusiness Council for Sustainable Development - WBCSD (2019), available at: https://www.wbcsd.org/Sector-Projects/Tire-Industry-Project/End-of-LifeTires-ELTs (2019)

End-of-LifeTires, WorldBusiness Council for Sustainable Development - WBCSD (2008), available at: http://www.rubberassociation.ca/files/ELT\%20Full\%20Report,\%202008.pdf (2008)

Farrag N. M., Ibrahim V. A. R., Elalfy A. M. (2017), "APPLICABILITY OF USING RECYCLED RUBBER-TIRE MATERIALS FOR ACOUSTIC INSULATION IN BARRIERS OF RESIDENTIAL AREAS IN EGYPT", ARPN Journal of Engineering and Applied Sciences, VOL. 12, №. 3, pp. $806-820$.

Marsili L., Coppola D., Bianchi N., Maltese S., Bianchi M., Fossi M.C. (2014), "Release of Polycyclic Aromatic Hydrocarbons and Heavy Metals from Rubber Crumb in Synthetic Turf Fields: Preliminary Hazard Assessment for Athletes", available at 
https://www.researchgate.net/publication/ 275581397 / Article in Environmental \& Analytical Toxicology ( January 2014)

Beausoleil M., Price K., Muller C. (2009), "Chemichals in outdoor artificial turf: A health risk for users?", Direction de santé publique de l'Agence de la santé et des services sociaux de Montréal (Public Health Branch, Montreal Health and Social Services Agency), Originally published in BISE (le Bulletin d'information en santé environnementale), Institut national de santé publique du Québec, Volume 19, Number 4-09/10/2008, June 2009.

Swedish Chemicals Inspecorate-e-mail: kemi@cm.se (2006), "Synthetic turf from a chemical perspective - a status report", available at https://www.kemi.se/global/pm/2006/pm-3-06-en.pdf, Sundbyberg No. 510 834, July 2006.

Cardno ChemRisk, Pittsburgh, PA (2013), "Review of the Human Health \& Ecological Safety of Exposure to Recycled Tire Rubber found at Playgrounds and Synthetic Turf Fields", available at https://www.groundsmartrubbermulch.com/docs/resources/HumanHealth-Eco-Safety-Exposure-to-RTR-at-Playgrounds-and-Synthetic-Turf-Fields.pdf,

August 2013

Boccaa B., Forte G., Petrucci F., Costantini S., Izzo P. (2009), "Metals contained and leached from rubber granulates used in synthetic turf areas", www.elsevier.com/locate/scitotenv / Elsevier, Science of total environment 407 (2009) 2183-2190

IARC (WORLD HEALTH ORGANIZATION INTERNATIONAL AGENCY FOR RESEARCH ON CANCER - IARC Monographs on the Evaluation of Carcinogenic Risks to Humans (1983), "Some Non-heterocyclic Polycyclic Aromatic Hydrocarbons and Some Related Exposures", VOLUME 92, Lyon, France, (1983), pp. 680

HRN EN ISO 717-1:2013 Acoustics, "Rating of sound insulation in buildings and of building elements", 2013

Gumiimex, "Proizvodnja gumeno-tehničkih proizvoda, obnova guma te recikliranje otpadnih auto guma", available at: http://gumiimpex.hr

European Commission (2007), "Report on the Implementation of Directive 2000/53/EC on End-Of-Life Vehicles for the period 2002-2005" , available at: www.ec.europa.eu/environment/waste/elv index.htm

Managing End-of-Life Tires (2008), ELT Full Report, available at: http://www.rubberassociation.ca/files/ELT\%20Full\%20Report,\%202008.pdf

Panko J., Kreider L.M., McAtee B., Marwood C. (2010), "Biological leaching of metals from respirable tire wear particles", available at: https://www.researchgate.net/publication/257556983 Chronic toxicity of tire and road wear particles to water- and sediment-dwelling organisms

McAtee B., Kreider L.M., Panko J., Finley B. (2012), "Chronic toxicity of tire and road wear particles to water- and sediment-dwelling organisms", ChemRisk®, available at: https://docs.wbcsd.org/2010/04/Bio Leaching Metals.pdf

Guleira S.P., Dutta R.K.,(2012), "Behaviour of fly ash-lime-gypsum composite mixed 
with treated tire chips”, ResearchGate, Geomechanics and Engineering, VOL. 14, №. 3, available at: https://www.researchgate.net/publication/292286443

Kowalska M., Chmielewski M., Guleira S.P., Dutta R.K.,(2017), "Mechanical Parameters of Rubber-Sand Mixtures for Numerical Analysis of a Road Embankment", IOP Conference Series: Materials Science and Engineering, WMCAUS, IOP Publishing, available at:

https://www.researchgate.net/publication/320861427 Mechanical Parameters of Rubbe r-Sand Mixtures for Numerical Analysis of a Road Embankment

Zaoiai S., Makani A., Tafraoui A., Benmerioul F. (2015), Optimization and mechanical characterization of self-compacting concrete incorporating rubber aggregates ", Asian journal of civil engineering (BHRC) Vol.17, No 6, pp 817-829, available at:

https://www.researchgate.net/publication/298076139 Optimization and mechanical char acterization of self-compacting concrete incorporating rubber aggregates

\section{About the author}

Andjelko Crnoja, Ph. Student of Odessa State Academy of Civil Engineering and Architecture in Odessa, Ukraine. Designer in the field of structural physics, narrow field noise protection. Research into the application of new recycled rubber-based materials in the field of structural structures. Research and application of recycled car tire panels to improve the sound insulation and other properties of lightweight metal structures. Development and application of new construction products based on recycled rubber for the protection of noisy noise sources in residential and industrial buildings. The author can be contacted at acrnoja@hotmail.com. 